\title{
Pigments of Trichophyta
}

\author{
By M. G. MCCABE AND P. D. MIER \\ Institute of Dermatology, St John's Hospital for Diseases of the \\ Skin, Lisle Street, London, W.C. 2
}

(Received 14 October 1959)

\begin{abstract}
SUMMARY
Pigments possessing the properties of anthraquinones were isolated from three species of the genus Trichophyton. These pigments were characterized by their absorption spectra, their colour changes with various reagents, and their $\boldsymbol{R}_{f}$ values on paper chromatography. Most of these pigments were common to more than one species.
\end{abstract}

\section{INTRODUCTION}

It has been known for many years that various species of the genus Trichophyton can synthesize materials which diffuse into the culture medium to give characteristic colours (Tate, 1929; Thomson, 1943). Pinetti (1949) showed that the colouring matter of $\boldsymbol{T}$. violaceum is a mixture of several closely related pigments; however, he achieved only a partial separation. Wirth, O'Brien, Schmidt \& Sohler (1957), using column chromatography, isolated three pigments from $T$. rubrum, and found traces of a number of others. Mier (1957), by using paper chromatography and fractional precipitation, obtained similar results.

The pigments isolated were very similar to the substituted anthraquinones which have been isolated from species of the genus Aspergillus, Penicillium, and other sources (Tatum, 1944; Birkinshaw, 1953; Stickings \& Raistrick, 1956). It was apparent that a more extensive survey of the trichophyton pigments was required as a preliminary to any work aimed at establishing their metabolic significance. It was also of more direct interest, since the pigmentation of colonies is used as a criterion of classification. The three species investigated and described here are Trichophyton mentagrophytes, $T$. violaceum and T. rubrum.

No attempt was made to elucidate the chemical structure of the pigments, and it was considered unnecessary to isolate large quantities of material: small agar cultures were used throughout. Fractional precipitation was used for the preliminary separation of the crude extracts, and paper chromatography provided a resolution of the pigments. Sufficient quantities of material were eluted from these chromatograms for the subsequent investigations.

\section{METHODS}

Organisms. Strains of each of the three species of fungi were obtained from two sources: the Department of Medical Mycology, Institute of Dermatology, London, and the Department of Medical Mycology, London School of Hygiene and Tropical Medicine. All cultures were grown on plates of Sabouraud's agar. The growth was 
harvested when a heavy pigmentation of the medium developed, but before any drying of the agar occurred.

Reagents were of A.R. grade. The light petroleum was of boiling range $60^{\circ}-80^{\circ}$. Absorption spectra were plotted in chloroform solution ('Spectrosol', Hopkin and Williams, London) using a Hilger 'Uvispek' spectrophotometer.

Experimental procedure. The pigments were extracted from the agar into chloroform by the method of Mier (1957). Methods of fractionation of the individual extracts are discussed below. The volumes of light petroleum and methanol required for optimum separations varied slightly according to the relative quantities of the pigments present. Typical values for these volumes are given in the text. Paper chromatography was conducted by upward flow of solvent, the paper used being Whatman no. 3 MM. The chromatograms were viewed against an illuminated screen, or alternatively under ultraviolet light, the pigments then appearing as dark bands. When dealing with very small amounts of material, the paper was sprayed with a solution of magnesium acetate in ethanol, the pigments appearing as more intense, distinctively coloured bands (Shibata, Takito \& Tanaka, 1950). The solvent systems used for chromatography were mixtures of light petroleum and chloroform. The effect of increasing the concentration of chloroform was to increase the $\boldsymbol{R}_{\boldsymbol{f}}$ values of the pigments. Thus by adjusting the solvent system it was possible to achieve an optimum resolution of any particular group of pigments. $\boldsymbol{R}_{f}$ values were also found to be influenced slightly by the amount of material applied to the paper or by the presence of other compounds. Therefore, when establishing the identity of two or more pigments (as described below) they were first isolated by preliminary chromatograms. The smallest quantity of each pigment which could readily be observed was then placed on a fresh paper and re-run. The pigments were eluted from the paper with chloroform and the eluates were used for measuring the absorption spectra and for observation of the colour reactions. Blank sections of the chromatography paper were similarly eluted and their absorption spectra were measured.

Colour reactions of the pigments were carried out by pipetting small portions of the eluate into the depressions of a glazed porcelain tile, allowing to dry and then adding a few drops of either $(a)$ glacial acetic acid, $(b) \mathrm{N}$-sodium hydroxide, $(c) \mathrm{N}$ sodium hydroxide saturated with sodium dithionite, or $(d)$ concentrated sulphuric acid.

Criteria of purity and identity. Two criteria of purity were adopted: (a) when no further resolution of the pigments could be achieved by paper chromatography using a range of solvents; and $(b)$ when no change in the absorption spectrum occurred following paper chromatography and elution, using at least two different solvents.

When pigments are reported identical, the following conditions were fulfilled: (a) the $\boldsymbol{R}_{f}$ values were identical over a range of solvents; (b) the absorption spectra were identical; $(c)$ the colour reactions with various reagents were the same.

\section{RESULTS}

Trichophyton mentagrophytes. A separation of the pigments into two groups was achieved by the addition of $10 \mathrm{vol}$. of methanol to the concentrated chloroform extract, a red-brown flocculent precipitate being obtained. This was centrifuged, and 
the precipitate washed with a further quantity of methanol. The bright yellow supernatant was evaporated to a small volume and chromatographed. The pigment band remained homogeneous using a range of solvents. This pigment $\left(A_{1}\right)$, was eluted and its absorption spectrum was plotted over the range $230-460 \mathrm{~m} \mu$. No change in the spectrum was observed on repeated chromatography using several solvents.

The precipitate from the methanol fractionation was re-dissolved in chloroform to give a bright orange-red solution. Chromatography again showed only one pigment (B) to be present. It was eluted and its absorption spectrum was plotted as before. A second fractionation from chloroform prior to chromatography caused no change in this curve.

Trichophyton violaceum. This contained a more complex mixture of pigments. The addition of 5 vol. of light petroleum to the concentrated chloroform extract effected a separation into two main groups, a brown precipitate being thrown down. The yellow supernatant was concentrated and chromatographed as for T. mentagrophytes; two pigments were found. The major component was a yellow compound $\left(\mathbf{A}_{2}\right)$, with a much smaller quantity of a yellow material running slightly ahead $\left(A_{1}\right)$. These two pigments were eluted separately and purified by further chromatography to constant absorption spectra.

The brown precipitate from the first fractionation was washed with light petroleum and re-dissolved in chloroform. This solution was further fractionated by the addition of $10 \mathrm{vol}$. of methanol, and the red-brown precipitate thus obtained was washed in methanol, re-dissolved in chloroform and chromatographed. The final supernatant was concentrated and chromatographed, the optimum solvent system being $\mathbf{3 0} \%$ light petroleum and $\mathbf{7 0} \%$ chloroform. Five components could be distinguished on the chromatogram, but the quantities represented only a small fraction of the original extract. Two of these pigments $\left(C_{1}\right.$ and $\left.C_{2}\right)$ were present in sufficient amount to be characterized by the methods described. In addition there were traces of an orange pigment running ahead of $\mathrm{C}_{1}$, a yellow-orange pigment running between $C_{1}$ and $C_{2}$ and a red purple pigment between $C_{2}$ and the origin.

Trichophyton rubrum. A separation of the pigments from this species has been described previously (Mier 1957, Wirth et al. 1957). The $\boldsymbol{R}_{f}$ values of the pigments were measured for a range of solvents, and the colour reactions previously obtained were extended. Pure specimens of the pigments were used as markers when running chromatograms of material from other species.

Distribution of the pigments. One pigment (B) was found to be common to all three species. Pigment $A_{1}$ was common to Trichophyton violaceum and T. mentagrophytes, while pigments $A_{2}, C_{1}$ and $C_{2}$ of $T$. violaceum were found identical to the three pigments previously isolated from $T$. rubrum and described as $\mathbf{A}, \mathbf{C}$ and 'yellow trace', respectively. T. violaceum showed traces of three other pigments not found in the other species. These results are summarized in Table 1. Essentially the same distribution of pigments was found in each strain of any one species; however, several strains of $\boldsymbol{T}$. mentagrophytes ceased to synthesize anthraquinone pigments on repeated subculturing on Sabouraud's medium. In these subcultures a yellow pigment was produced which could not be extracted into chloroform and did not give any colour reactions with alkali. This pigment was not examined further. The results quoted for strains E. 5836 and E. 6302 were obtained using 
freshly isolated cultures. This lability of pigmentation was not shown by either T. violaceum or T. rubrum.

Table 1. Distribution of pigments among the strains of fungi examined

\begin{tabular}{|c|c|c|c|c|c|c|c|}
\hline \multirow[b]{2}{*}{ Fungus } & \multirow{2}{*}{$\begin{array}{c}\text { Strain } \\
\text { no.* }\end{array}$} & \multicolumn{6}{|c|}{ Pigment $\uparrow$} \\
\hline & & $\mathbf{A}_{1}$ & $\mathbf{A}_{\mathbf{2}}$ & $\mathbf{B}$ & $\mathbf{C}_{1}$ & $\mathbf{C}_{2}$ & Others \\
\hline Trichophyton violaceum & $\begin{array}{l}\text { 7794 } \\
\text { D 488 } \\
\text { D 498 }\end{array}$ & $\begin{array}{l}+ \\
+ \\
+\end{array}$ & $\begin{array}{l}+++ \\
+++ \\
+++\end{array}$ & $\begin{array}{l}+ \\
+ \\
+\end{array}$ & $\begin{array}{l}+ \\
+ \\
+\end{array}$ & $\begin{array}{l}+ \\
+ \\
+\end{array}$ & $\begin{array}{l}\text { Traces } \\
\text { Traces } \\
\text { Traces }\end{array}$ \\
\hline T. rubrum & $\begin{array}{l}\text { E 6606 } \\
\text { D 358 } \\
\text { D 360 }\end{array}$ & $\dot{.}$ & $\begin{array}{c}+ \\
++ \\
++\end{array}$ & $\begin{array}{l}++ \\
++ \\
++\end{array}$ & $\begin{array}{c}++ \\
+ \\
+\end{array}$ & $\begin{array}{l}+ \\
+ \\
+\end{array}$ & $\dot{.}$ \\
\hline T. mentagrophytes & $\begin{array}{l}\text { E } 5836 \\
\text { E 6302 }\end{array}$ & $\begin{array}{l}++ \\
++\end{array}$ & . & $\begin{array}{l}++ \\
++\end{array}$ & . & . & . \\
\hline
\end{tabular}

* The strains prefixed ' $D$ ' were obtained from the London School of Hygiene and Tropical Medicine, the remainder were isolated at the Institute of Dermatology.

+ Pigment constitutes bulk of extract, +++ ; pigment present in appreciable quantity, ++ ; pigment present in the minimum quantity for characterization, + .

Physical and chemical properties of the pigments. The $\boldsymbol{R}_{f}$ values of the pigments are shown in Table 2. The variation of $\boldsymbol{R}_{f}$ values with solvent composition is illustrated graphically in Fig. 1. The absorption spectra of the pigments are shown in Figs. 2-6. The source of the pigment is indicated on the diagrams. The eluate from sections of the chromatography paper was found to have a negligible absorption over the range investigated.

Table 2. The $\boldsymbol{R}_{f}$ values of the pigments in various chloroform-light petroleum mixtures

\begin{tabular}{|c|c|c|c|c|c|}
\hline $\begin{array}{l}\text { Percentage } \\
\text { chloroform } \\
(\mathrm{v} / \mathrm{v})\end{array}$ & $\mathbf{A}_{1}$ & $\mathbf{A}_{2}$ & B & $\mathbf{C}_{1}$ & $\mathrm{C}_{2}$ \\
\hline 15 & $0 \cdot 14$ & & . & . & . \\
\hline 20 & $0 \cdot 20$ & 0.08 & . & . & . \\
\hline 25 & 0.28 & $0 \cdot 13$ & . & . & . \\
\hline 30 & $0 \cdot 40$ & 0.22 & 0.04 & . & . \\
\hline 35 & 0.54 & 0.35 & 0.07 & . & . \\
\hline 40 & $0 \cdot 66$ & 0.48 & $0 \cdot 14$ & . & . \\
\hline 45 & 0.74 & 0.61 & 0.25 & & . \\
\hline 50 & 0.79 & 0.72 & 0.39 & $0 \cdot 10$ & . \\
\hline$=5$ & 0.84 & 0.81 & 0.53 & 0.17 & \\
\hline 60 & 0.88 & 0.86 & 0.66 & 0.27 & 0.05 \\
\hline 65 & 0.91 & 0.90 & 0.76 & $0 \cdot 40$ & 0.08 \\
\hline 70 & 0.93 & 0.93 & 0.82 & 0.50 & 0.12 \\
\hline 75 & . & • & 0.86 & 0.58 & $0 \cdot 17$ \\
\hline 80 & . & . & . & $0 \cdot 65$ & 0.23 \\
\hline 85 & . & . & . & 0.71 & 0.30 \\
\hline 90 & . & . & . & 0.76 & $\mathbf{0 . 3 6}$ \\
\hline
\end{tabular}




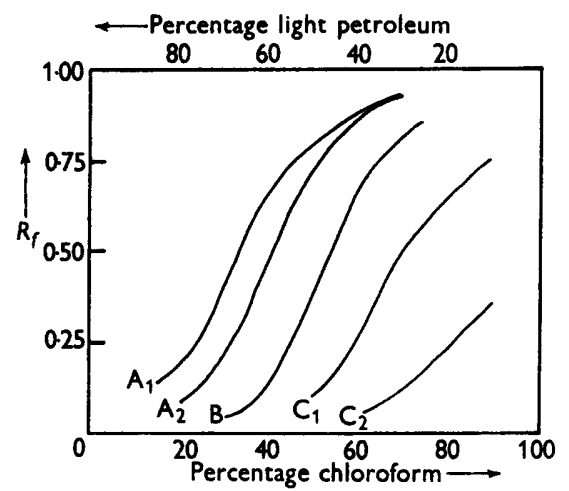

Fig. 1

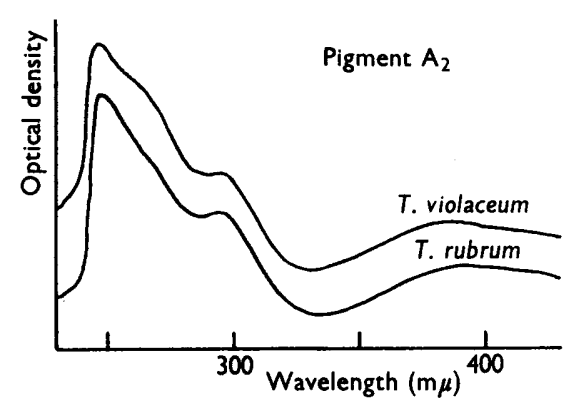

Fig. 3

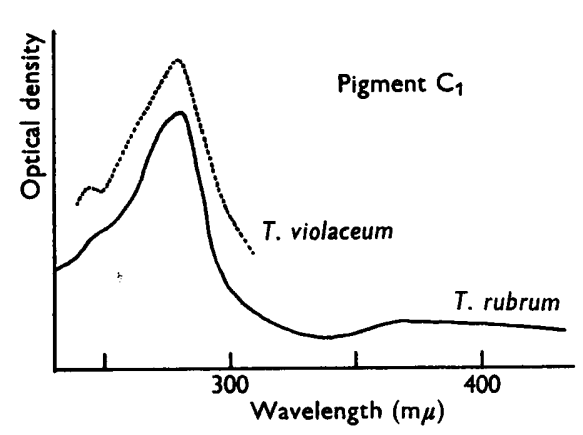

Fig. 5

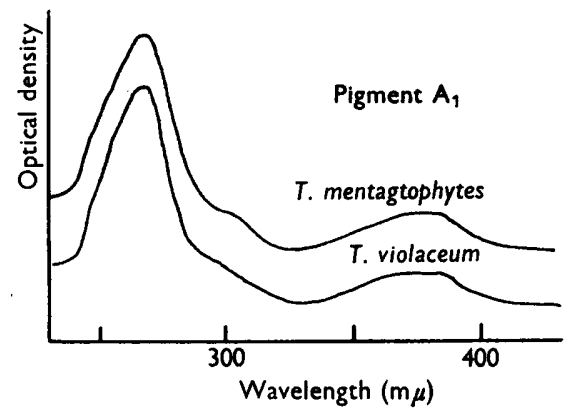

Fig. 2

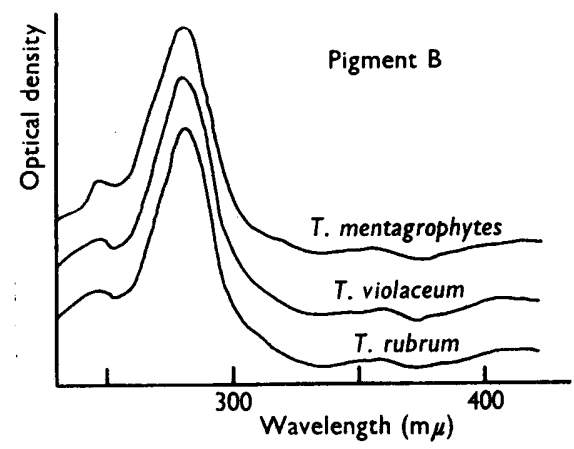

Fig. 4

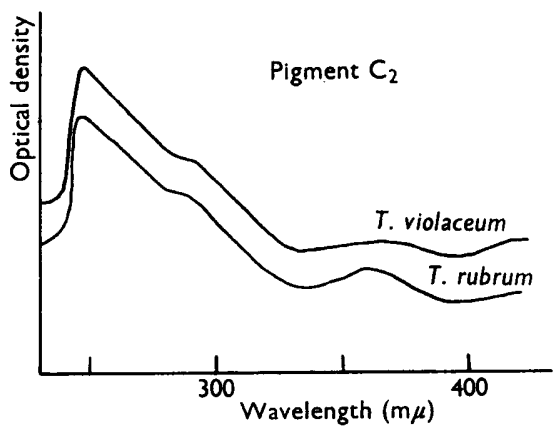

Fig. 6

Fig. 1. Variation of $\boldsymbol{R}_{f}$ values of the pigments with varying solvent composition.

Figs. 2-6. Ultraviolet absorption spectra of the pigments in chloroform solution. 
Table 3. Colour reactions of the pigments with various reagents

\begin{tabular}{|c|c|c|c|c|c|}
\hline Pigment & $\mathbf{A}_{1}$ & $\mathbf{A}_{2}$ & B & $\mathrm{C}_{\mathbf{1}}$ & $\mathbf{C}_{2}$ \\
\hline $\begin{array}{l}\text { Solution in chloroform } \\
\text { Solution in glacial acetic }\end{array}$ & $\begin{array}{l}\text { Deep yellow } \\
\text { Yellow }\end{array}$ & $\begin{array}{l}\text { Bright yellow } \\
\text { Yellow }\end{array}$ & $\begin{array}{l}\text { Orange-red } \\
\text { Yellow }\end{array}$ & $\begin{array}{l}\text { Purple } \\
\text { Wine red }\end{array}$ & $\begin{array}{l}\text { Yellow } \\
\text { Yellow }\end{array}$ \\
\hline $\begin{array}{l}\text { Solution in } 1 \mathrm{~N} \text {-sodium } \\
\text { hydroxide }\end{array}$ & Mauve & Mauve & Purple & Blue & Yellow \\
\hline $\begin{array}{l}\text { Above solution saturated } \\
\text { with sodium dithionite }\end{array}$ & Yellow & Yellow & Deep yellow & Amber & Purple \\
\hline $\begin{array}{l}\text { Solution in concentrated } \\
\text { sulphuric acid }\end{array}$ & Peach red & Cherry red & Mauve & $\begin{array}{l}\text { Green } \\
\text { (slowly) }\end{array}$ & Orange \\
\hline $\begin{array}{l}\text { Colour on paper after } \\
\text { magnesium acetate spray }\end{array}$ & Salmon pink & Raspberry & Orange & Blue & Mauve \\
\hline
\end{tabular}

\section{DISCUSSION}

The accumulation of pigments by the three species of Trichophyton, and the similarity of their distribution provide additional evidence for the botanical classification. Clearly the use of analytical techniques of this kind may be of use in diagnostic medical mycology.

Although no structures have been established for the compounds described, their chemical reactions and absorption spectra suggest that they are anthraquinone derivatives, many of which have been previously described. However, no evidence has been found of the isolation of these particular pigments from other sources.

The significance of the pigments is a matter of conjecture. Foster (1958) has pointed out that the accumulation of metabolites by the microfungi can be useful in elucidating new metabolic pathways. The oxidation-reduction properties of the trichophyton pigments suggest a role in hydrogen transport. It has been shown in this laboratory that under anaerobic conditions the pigments deposited in the medium are reduced by the fungi. In the presence of air re-oxidation takes place.

Raistrick and other workers have found that certain fungal anthraquinones possess powerful bacteriostatic properties. If bacteriostasis were their sole function, however, it is difficult to see why the property cannot be more generally demonstrated in this group of compounds. No definite answer can be given on the evidence at present available.

The authors wish to acknowledge the kindness of Miss B. M. Partridge, M.A., and Miss N. Dzawachiszwili, B.Sc., of the Institute of Dermatology, and Miss P. M. Stockdale, B.Sc., of the London School of Hygiene and Tropical Medicine, in providing the specimens of fungus.

\section{REFERENCES}

Birkinshaw, J. H. (1953). Chemistry of the Fungi. Annu. Rev. Biochem. 13, 390. Foster, J. W. (1958). An evaluation of the role of molds in the comparative biochemistry of carbohydrate oxidation. Tex. Rep. Biol. Med. 16, 79.

Mrer, P. D. (1957). Pigments in Trichophyton rubrum. Nature, Lond. 179, 1084.

Pinetri, P. (1949). Studi sulla pigmento-genesi di Trichophyton violaceum. Nota II. Estrazione e purificazione del pigmento. Rass. med. Sarda, 51, 179.

Shibata, S., Takito, M. \& Tanaka, O. (1950). Paper chromatography of anthraquinone pigments. J. Amer. Chem. Soc. $72,7289$. 
Stickings, C. E. \& Raistrick, H. (1956). Chemistry of the fungi. Annu. Rev. Biochem. 25, 225.

TATE, P. (1929). The dermatophytes, or ringworm fungi. Biol. Rev. 4, 41.

TAtum, E. L. (1944). Biochemistry of the fungi. Annu. Rev. Biochem. 13, 667 .

Tromson, K. W. (1943). Report of the conference on dermatophytes. Div. Med. Sci.: Nat. Res. Council.

Wirth, J. C., O'Brien, P. J., Schmidt, F. L. \& Sohler, A. (1957). The isolation in crystalline form of some of the pigments of Trichophyton rubrum. J. invest. Derm. 29, 47. 